\title{
Impediments to the Implementation of CLT Principles at the SSC Level in Bangladesh: A Case Study
}

\author{
Mohammed Humayun Kabir'1, Forhad Jamila², Nahida Sultana ${ }^{2}$ \\ ${ }^{1}$ Department of English Language and Literature, International Islamic University Chittagong, Chittagong, Bangladesh \\ ${ }^{2}$ Department of Humanities, Chittagong University of Engineering and Technology, Chittagong, Bangladesh \\ Email: humayun002003@yahoo.com
}

How to cite this paper: Kabir, M. H., Jamila, F., \& Sultana, N. (2020). Impediments to the Implementation of CLT Principles at the SSC Level in Bangladesh: A Case Study. Creative Education, 11, 1090-1106. https://doi.org/10.4236/ce.2020.117081

Received: June 21, 2020

Accepted: July 20, 2020

Published: July 23, 2020

Copyright ( 2020 by author(s) and Scientific Research Publishing Inc. This work is licensed under the Creative Commons Attribution International License (CC BY 4.0).

http://creativecommons.org/licenses/by/4.0/ (c) (i) Open Access

\begin{abstract}
The Ministry of Education of Bangladesh introduced Communicative Language Teaching (CLT) at secondary level by replacing Grammar Translation Method (GTM) in 1995. However, a body of studies found that principles of the CLT-based curriculum are not properly implemented so far. As a consequence, a wide gap is noticed between the policy and practice in teaching of English language. So, it is important to identify the reasons or factors that hinder the implantation of CLT at the secondary level education. This qualitative study was designed with a purpose to ascertain the impediments those hinder the implementation of CLT at the secondary level in Bangladesh. It used two methods namely classroom observation and practicing teachers' interview and then the findings were triangulated to find a comprehensive answer to the research questions. The identified impediments may be taken into consideration and a solution to the research problem may be found.
\end{abstract}

\section{Keywords}

CLT, GTM, Communicative Competence, Curriculum, SSC, Learner-Centeredness

\section{Introduction}

The Ministry of Education of Bangladesh adopted CLT-based English curriculum in 1995. The goal of the present curriculum is to develop the communicative competence of the learners. To achieve this goal, English syllabus was improvised by National Curriculum and Textbook Board (NCTB). By the end of secondary level, students are expected to have an overall mastery over the four Eng- 
lish language skills i.e. reading, writing, listening and speaking. The chief purpose of the new language teaching curriculum was to promote "communicative competence" through the practice of four language skills. Jamila and Kabir (2020) posit that "The purpose of introducing CLT is to make English language teaching and learning more effective as the demand of proficiency in English language is ever growing not only in Bangladesh but also beyond the territory of the country" (p. 559).

Despite the fact that the official curricular documents claim that CLT was introduced more than two decades ago, schools fail to implement the principles of this new language teaching approach. Sultana (2018) found that CLT principles are not followed entirely in the schools and colleges till date. The implementation of CLT in secondary and higher secondary levels is doubted (Billah, 2015; Ali \& Walker, 2014; Hamid \& Baldauf, 2008; Kabir, 2015a). Understandably, the incomplete practice of a language teaching methodology cannot bring desired success. As a consequence, the success of CLT in terms of developing communicative competence is questioned.

It was expected that post CLT era of English language teaching and learning outcome would be better in terms of developing language proficiency among the learners. Host of studies (Hamid \& Baldauf, 2008; Kabir, 2008; Kabir, 2009; Jamila \& Kabir, 2020) show that CLT is not as effective as it was thought of in the context of Bangladesh. The quality of English language teaching and testing at Primary, Secondary and Higher Secondary levels is questioned by a host of researchers (Kabir, 2015a, 2015b; Billah, 2015; Mariyam et al., 2015).

The influence of Grammar Translation Method (GTM) is still noticed in the classroom teaching and learning activities. It is also observed that "the teaching materials that are randomly used are not authentic materials. This is obviously contradictory with the principles of CLT" (Kabir \& Saad, 2020: p. 17). It is observed that previously followed GTM has a strong influence on teachers (Begum \& Farooqui, 2008) when they are supposed to teach and implement a CLT curriculum (Ali, Hamid, \& Hardy, 2018; Rahman, Sing, \& Pandian, 2018). Studies revealed that teachers were unready for this language teaching approach (Rahman, Sing, \& Pandian, 2018; Hamid \& Baldauf, 2008). There are ample indications that this CLT curriculum is being partly implemented throughout the country.

Newspaper reports publish the findings of different studies, seminars and round-table discussions regularly which identify the falling standard of the students' English language proficiency. From the following reports, it is revealed that secondary English teachers are incapable to uphold curriculum guidelines as they cannot implement creative method. It suggests that they are unable to conduct language teaching and incompetent enough to design tests by following the curriculum which implies that "creativity and critical thinking through English language" (NCTB, 2012: p. 74) should be developed. On May 8, 2019, The Daily Star, in its editorial column published a note after the publication of SSC result of 2019. In this column, the editor emphasised that quality of education should be ensured. It expresses that "the high pass rates don't necessarily mean that the 
quality of education is better. So, we should focus on improving the quality of education" (Anam, 2019). This comment implies that still there are scopes to raise the standard of education what the government needs to address immediately. Pervez (2016) explored that both teachers and students commonly depend on commercial guidebooks for class/test preparation, students memorise answers to the probable questions from guide/notebooks though the creative method was introduced to discourage rote learning and stop guide/notebook and private coaching business.

The discussion made above depicted that SSC EFL tests' nature and technique affect classroom teaching and consequently, it affects the learning of English. Critics believe that the rise of pass rates in SSC examinations does not really mean that there is a dramatic improvement in teaching and learning at SSC level. There is a tacit indication that flawed test is responsible for producing the wrong result.

\section{Significance of the Study}

The education system in Bangladesh is based on a 3-tiered system: primary, secondary and higher secondary. Secondary education is the biggest schooling stage in the educational structure in Bangladesh (Begum \& Farooqui, 2008), which has been identified as one of the priority areas in 2017/18 budget. Students sit for the most important school leaving public examination at the end of grade 10, which is known as the Secondary School Certificate (SSC) examination. This is a 2 years program comprises of grades 9 and 10. Students study English as one of the compulsory subjects at the SSC level. Among all the examinations, English is considered the most important and tough to pass. This high-stakes test is an achievement test in nature and takes place only once in a year. Thus, SSC which is an "O" level equivalent test that directly influences students' study and life chances. It plays a gate-keeping role in the career of a student. It is important to explore the reasons why the objectives of CLT are not achieved so far. So study should be undertaken to identify the factors that hinder the implementation of CLT at SSC level.

\section{The Rationale of the Study}

More than two decades passed since the introduction of CLT based curriculum at SSC level. There are indications that CLT principles are not implemented so far. Haider and Chowdhury (2012) opined that "the features of CLT and the criteria set for teaching and learning in the curriculum documents provide the opportunities for the teachers and learners to improve their practices and attitudes. However, the present realities do not replicate the methodological aspects suggested in the curriculum documents" (p. 18). That is why it may be presumed that CLT exists in curricular documents but it is not properly reflected inside the classroom teaching and learning activities and testing practices. Seemingly, there is little evidence to suggest that the new language teaching policy brought about any significant changes in teaching practice at the school level.

An inclusive study on the impediments to the implementation of CLT in the 
context of Bangladesh is not done so far, as far as my knowledge goes. It is important to explore the impediments that hinder the implementation of CLT at the secondary level. So, it is expected that the authority concerned will find the valid and real reasons that obstruct the smooth implementation of the curriculum.

\section{Research questions}

1) To what extent is CLT based curriculum functional at secondary level in Bangladesh?

2) What are the main impediments to the implementation of CLT at SSC level in Bangladesh?

\section{Literature Review}

\subsection{SSC English Curriculum}

It is crucial to explore the core aspects of the National Curriculum (NC). In this discussion the salient aspects of the curriculum are included. "The Secondary Curriculum was revised in 2012 in line with the aims and objectives of the education policy” (In, Preface, Teacher's Curriculum Guide, 2013). National Curriculum 2012 puts "special emphasis on four skills such as listening, speaking, reading and writing instead of content memorization in case of teaching and learning of mother tongue, Bangla and International language, English" (NCTB, 2012: p. 10). It is clear that language teaching paradigm-shifting i.e. shifting from GTM to CLT required a remarkable change in pedagogy. Earlier, when GTM was in practice only two major language skills e.g. writing and reading skills had been taught and tested. But the present curriculum has adopted CLT approach. Hence, National Curriculum 2012 declares that "all four basic language skills would be practised in class" (NCTB, 2012: p. 73). The new curriculum recommends establishing learner-centred classroom teaching in place of traditionally practised teacher-centred teaching culture. It directs that" interactive activities should be carried out between teachers and students, and more importantly between students and students" (p. 73).

The policymakers of National Curriculum 2012 maintained that learner's creativity and critical thinking is a crucial requirement for developing communication skills among the learners. The present curriculum will "develop creativity and critical thinking through English language" (NCTB, 2012: p. 74). Present curriculum was designed "to help learners acquire the basic skills of English language for effective communications at different spheres including contemporary workplaces and higher education" (NCTB, 2012: p. 11). The traditional lecture-based teaching failed to develop communication skills among the learners despite that they study English from Grade-I to Grade-XII. To address this problem CLT was introduced which necessitated that various types of classroom activities should be included so that students find opportunities to engage themselves. It recommends that "class activities should be varied. Learners' attention 
can be drawn through discussions, group works, story writing, drawing, debates, role-play, practical work, question answer, demonstrations..." (NCTB, 2012: p. 17). The curriculum documents suggest that "there will also be provisions for using supplementary reading materials to develop learners' reading skill" (NCTB, 2012: p. 73). It also reiterates that communicative English grammar will be taught. Therefore, instead of lecture-based and teacher-centred teaching, learner's participation is emphasised.

As per the guidelines of the present curriculum four major language skills will receive equal attention in teaching. It will enable learners to make effective communication in real-life situations. The objectives are featured in the following manner:

"To acquire competence in all four language skills".

- To use the competence for effective communication in real-life situations at pre-intermediate level.

- To acquire necessary grammar competence in English language.

- To develop creativity and critical thinking through English language.

- To use language skills for utilizing information technology.

- To be skilled human resources by using English language skills" (NCTB, 2012: p. 74).

The above discussion revealed that the functional curriculum is completely a CLT-based curriculum which replaced a GTM-based curriculum in Bangladesh. The following discussion clarifies the salient features of CLT approach in language teaching.

\subsection{Features of Communicative Language Teaching (CLT)}

The CLT approach underlines paramount importance on developing communicative competence. Hymes clarified it (communicative competence) as "the ability to use linguistic knowledge of language appropriately in a variety of social situations" (Hymes, 1979: p. 3). Hymes prioritises to develop communication skills rather than mastering linguistic knowledge which underpins that it is not essential to master the elements/building blocks of the language and also not necessary to learn the rules by which these elements are combined for making communication. CLT aims to "1) make communicative competence the goal of language teaching; and 2) develop procedures for the teaching of the four language skills that acknowledge the interdependence of language and communication" (Eisenchlas, 2010: p. 15).

Contextual limitations, the status of the target language, curricular goals, the availability of teaching materials available, learners' needs and demands determine the language teaching policy. Wei, Lin, and Litton (2018) opined that CLT has some salient features which have distinguished them from other language teaching approaches. Those features are:

1) Communicative classroom activities, 2) Learner-centred approach, 3) Authentic teaching materials, 4) Error toleration, 5) Teachers as facilitators, and 
6) Fluency above accuracy. It indicates that a context where CLT is functional, language teaching should be directed to develop communicative competence among the users which enables the learners to produce contextually appropriate language.

The above discussion revealed the most distinguished features of CLT. It is already mentioned that the curriculum designers of Bangladesh imposed a CLT based curriculum in 1996. In the context of Bangladesh, it is evident that the implementation of CLT poses some formidable challenges as the ground reality is different. That is why the following discussion portrays the education system of Bangladesh.

\subsection{Introduction of CLT in Bangladesh}

CLT is not accepted cordially by the teachers in Bangladesh and it is not truly practised in the schools. In the beginning CLT was opposed by the traditional English teachers because they were not ready for something which was entirely new to them (Rahman, Sing, \& Pandian, 2018). Begum and Farooqui (2008) found that though communicative approaches have been introduced in the language curriculum, most teachers prefer to follow the traditional grammar-translation method. Researchers identified that the functional curriculum has been implemented partly which can be considered as a possible reason of the current state of failure of the CLT approach in Bangladesh (Rahman \& Pandian, 2018, Ali, Hamid, \& Hardy, 2018). Indeed, when CLT was introduced in Bangladesh, it is assumed that the education administration failed to address some vital issues including teacher preparation for implementing education policy and test reformation. As a result, the imposition of CLT has affected language teaching and learning adversely. It is commonly believed that the CLT approach has failed so far to bring the expected changes in the existing English teaching and learning situation.

Studies found that the teachers still teach the students as they were taught by their teachers where rote learning is encouraged and practised (see also: Ali \& Walker, 2014). Test score is the most important issue for all. Begum and Farooqui (2008) also posit that teachers' goal is to prepare the students for the impending test so that students can obtain higher scores in the examination.

It appears that even after more than two decades of the introduction of CLT, the English teachers are unaware of the objectives of the English curriculum. The innovation in English language teaching curriculum was not clear to most of the teachers. Sultana (2019: p. 4) observes that "Even though a CLT-based curriculum has been in operation in this country for the last two decades, the communicative purpose of English teaching and learning apparently was never achieved".

Arguably, the policymakers of Bangladesh were largely responsible for this mismatch between the curriculum and the teaching and testing of English. It could not be denied that ground realities were not duly considered when CLT was introduced at secondary level education in Bangladesh. 


\section{Research Methodology}

This study was framed in order to determine the factors that hinder the implementation process of CLT at schools and the implementation of a communicative test at SSC level in Bangladesh. Since this study aims to find the answers to research questions of a qualitative nature, we adopted a qualitative research approach to collect and interpret the data. The design of the study was qualitative to gain a deeper understanding of the context and the participants. Marshall and Rossman (1989: p. 42) maintain "Researchers should design the study according to the research questions they seek to answer". It is also agreed that "knowing what you want to find out leads inexorably to the question of how you will get the information" (Miles \& Huberman, 1994: p. 42, cited in Silverman, 2000: p. 88). Thus, referring to the two research questions that have been designed in line with the objectives of the study.

\subsection{Research Context}

English language teaching (ELT) always has been an area of challenge in Bangladesh regardless of various attempts at curriculum reform (Rahman \& Pandian, 2018). Even though a CLT-based curriculum has been in operation in this country for the last two decades, the communicative purpose of English teaching and learning apparently was never achieved. Instead, the standards of English have degraded over the last few years rather than showing evidence of improvement. Some studies (Jamila \& Kabir 2020; Islam, 2015; Rahman, 2015) have suggested a strong presence of teaching to the test in teachers' classroom practices. Classroom English teachers are responsible for designing various internal examinations, and a few of them even serve on examination boards as question setters. Consequently, it is expected that teachers' classroom instruction would be largely molded by their assessment practices.

\subsection{Data Collection Methodology}

Here data were collected from participants to determine the barriers that inhibit the implementation of CLT based teaching and testing in Bangladesh. By observing English classes and interviewing those observed teachers data were collected.

\section{Participants}

As this study adopted a qualitative approach, it involves a limited number of participants that can really give insights to the phenomenon at hand (Bloomberg \& Volpe, 2018; Creswell, 2013). However, the participants should be "rich informants" (Punch, 2005). A purposive sampling technique was used to select the participants of this study. The informants in purposive sampling are members of the population, who know well about the context and are willing to provide the needed information based on their experience and knowledge. Dolores and Tongco (2007) hold that "the purposive sampling technique, also called judgment sampling, is the deliberate choice of an informant due to the qualities the 
informant possesses...the researcher decides what needs to be known and sets out to find people who can and are willing to provide the information by virtue of knowledge or experience" (p. 147).

The sample informants of this study are the Bangladeshi secondary level English teachers who work in Chittagong region under Chittagong Education board. The teachers are engaged in teaching and assessment procedure at SSC level. To conduct the study we decided to use two methods-classroom observation and interview analysis. The research participants in this study are directly involved in the English language teaching, testing and learning experiences at the secondary level in Bangladesh. Same participants were involved in the interview and observation.

Ten secondary school English teachers (6 male and 4 female) from Chittagong city were invited to participate in this study. Based on the researchers' experiences of the complexity in participant recruitment in Bangladesh, ten was expected to be a reasonable number. They agreed to be interviewed provided that their identities would not be disclosed. They all had teaching experience ranging from 6 years to 22 years. All 10 teachers in the sample possessed Master in Arts degree. In addition, these teachers had attended a limited number of workshops related to teaching. These teacher participants had experience in preparing internal examinations, and three teachers (T2) also had worked as the question setters at the examination board in different years.

\subsection{Instrumentation and Data Collection}

Observation has been found as one of the vital methods in this study. I translated the experiences that I gathered during classroom teaching observations that I carried out in four secondary (two government and two nongovernment) schools located in Chittagong city. I wrote a letter to the office of the concerned Head Master/Mistress of those schools seeking their permission to observe teaching of English teachers. After obtaining Head Master's/Mistress's permission another letter (plain language statement) accompanying consent form was written to the English teachers narrating them the objectives of the study and their permission was sought to observe their classes. On the appointed day the classes of those teachers were observed. During my stay in the class, I noted all the matters and issues that are relevant to my study. I observed the classes of those teachers only whom I interviewed later on. I spent almost four weeks from half-yearly teaching session which is the middle of the academic year. At least two periods (the duration each period is 45 minutes) of English $1^{\text {st }}$ Paper and English $2^{\text {nd }}$ Paper classes of each school were observed. In total 10 classes were observed.

During observation session the class duration, the content/topic taught, medium of instruction along with absentees and presentees in each class were carefully noted. This was followed by a calculation of the average amount of time that the observed teachers devoted to teaching. It is noteworthy to mention that Communicative Orientation of Language Teaching Observation Scheme (COLT observation scheme, 1995) was used to collect data to see to what extent present 
SSC EFL tests might influence teaching methodology (see also Pan, 2013; Taqizadeh \& Birjandi, 2015). COLT observation scheme includes the following areas:

1) Skills (i.e. listening, speaking, reading and writing) focused on;

2) Test preparation activities;

3) Interaction between teachers and students (i.e. teacher-centred or student-centred interaction); and

4) The medium of instruction.

Interviews with teachers were arranged just after finishing the classroom observation. Well ahead of the interview, every teacher participant was given a plain language statement and a consent form. The plain language statement includes: 1) the invitation to be a participant; 2) the research project; 3) what will he/she have to do; 4) intention of protecting his/her anonymity; 5) that participation is voluntary and withdrawal at any stage is allowed and 6) the researchers' particulars. The information is rather similar in the consent form but different presentation as a plain language statement aims to invite and inform whereas a consent form functions as an expression of the participant's willingness to participate and acknowledgement of the procedures involved.

\subsection{Data Collection Activities}

Qualitative researchers advocate that data analysis should have started concurrently with the data gathering method (Bogdan \& Biklen 2007; Merriam, 2009 cited in Saad 2014). Classroom teaching observation and interviews were conducted by the first author between April to June, 2019. Before interviewing, the participating teachers were asked about their educational backgrounds and teaching experiences. The interviews were audio recorded using an android mobile phone. After collecting data a comprehensive, rigorous and systematic data analysis was conducted.

\subsubsection{Data Analysis Procedures}

All interviews were transcribed and read while listening to the audio recording. This exercise was particularly helpful in identifying elements of the recordings, such as a sarcastic tone, that were not apparent from the written transcript.

\subsubsection{Data Collection Plan}

Table 1 presented below illustrates how the present researcher found the answer to research questions of this study.

Table 1. Data used to answer the RQs.

\begin{tabular}{|c|c|c|c|}
\hline Research Objectives & Research Questions & Methods & Data sources \\
\hline $\begin{array}{l}\text { To identify the } \\
\text { impediments to } \\
\text { the implementation } \\
\text { of communicative } \\
\text { language teaching } \\
\text { in Bangladesh. }\end{array}$ & $\begin{array}{l}\text { 1) To what extent is CLT based curriculum } \\
\text { functional at secondary level in Bangladesh? } \\
\text { 2) What are the main impediments to the } \\
\text { implementation of CLT at SSC level in } \\
\text { Bangladesh? }\end{array}$ & Observation & $\begin{array}{c}\text { Classroom } \\
\text { Observation }\end{array}$ \\
\hline
\end{tabular}


The research questions were designed to identify to what extent the CLT based curriculum is functional at the secondary level and also to ascertain the factors that may be considered as stumbling blocks in implementing CLT based curriculum. The data analysis made below had explored that teaching and testing of English at SSC level are far removed from the functional curriculum guidelines. If teaching is not directed to achieve the curricular goals and objectives and if tests are not developed in line with the curricular statements, it may be assumed that learning will surely be affected. In addition, the data analysis identified the factors that hinder the implementation of the curriculum.

\section{Data Analysis}

In this part, first, observational data were analysed and then interview responses were considered. During observation and interview, we tried to figure out two vital aspects. First, how far CLT principles were upheld, second, what hindered the implementation of CLT. So our attention was confined to Class size, teachers' proficiency, mode of interaction during class, student-teacher relation, used materials, test's influence, acoustic facility of the schools and so on.

\subsection{Analysis of Classroom Teaching Observations: A Look into the Classroom}

It was mentioned that 10 classroom teaching sessions in different four schools were observed when teaching activities were being conducted. It became essential to observe classes to identify the impediments to CLT and also to verify the findings of the above reports. The following part includes classroom observation. Here, it is worthy to mention that I pointed out at this point those observed issues which are relevant to the above research questions. Table 2 just below shows the observed salient aspects/features linked to the above-noted research question during classroom observation:

Table 2. Salient aspects of teaching observations.

\begin{tabular}{|c|c|}
\hline $\begin{array}{l}\text { No. of Observed } \\
\text { salient aspects }\end{array}$ & Aspects found \\
\hline Observed aspect- $\mathrm{i}$ & Class size: Over crowed \\
\hline Observed aspect-ii & Teacher's proficiency: Lack of efficient teachers \\
\hline Observed aspect-iii & Language used: Mostly L1 (Bangla) \\
\hline Observed aspect-iv & $\begin{array}{l}\text { Teaching-learning practice: Teacher dominated teaching-learning } \\
\text { culture }\end{array}$ \\
\hline Observed aspect-v & $\begin{array}{l}\text { Teaching-learning materials: Mostly commercially publish materials, } \\
\text { no use of authentic materials }\end{array}$ \\
\hline Observed aspect-vi & Listening/Speaking facility: Lack of acoustic facility in schools \\
\hline Observed aspect-vii & $\begin{array}{l}\text { Teaching practice: Exam-oriented teaching and grammar was } \\
\text { taught in a didactic way }\end{array}$ \\
\hline Observed aspect-viii & Students' participation: Hardly found \\
\hline
\end{tabular}


The above table exhibits that observation scheme focused on eight vital aspects which were linked with the stated research questions. It was found that SSC classrooms were overcrowded with students. It was identified that very large number of students were registered where every single class was comprised of 80 to 90 students. Teachers' inefficiency in terms of language proficiency and skill to implement CLT was perceptibly poor. They hardly used English to communicate with the students and Bangla was the most widely used language. Observation sessions also revealed that classroom teaching was teacher-centred. Students were passive learners. Teachers read some passages and interpreted mostly in Bangla. Only those reading, writing and grammar items were found to teach which are commonly found in the SSC exam. In every observation sessions I noticed that test-related items got preference in the classroom. I checked the class routine and observed that there was no class on speaking and listening skills. I observed that only reading, writing and grammar skills are taught in the class. Most of the classrooms lacked acoustic facilities and commercial teaching materials (Guide/notebooks) were randomly used to teach Reading and Writing skills which is a convention of the traditional testing.

It was further noticed that commercially published teaching materials were frequently used instead of NCTB materials. There was a scarcity of acoustic facilities in the classes. Classroom teaching is mostly influenced by the SSC EFL tests. We observed that students were not involved in the language skills practice and though the curriculum suggested to include such class activities as: asking and answering, role playing/acting out, working in pairs/groups or working individually, describing people and objects, doing drills, participating in debates, etc., we hardly observed teachers to abide by the guidelines of the curriculum.

The findings of the above classroom observational data have to be judged by making a comparison between the teachers views regarding the impediments to the implementation of CLT at SSC level.

\subsection{Analysis of Teacher Interview: From the Teachers' Perspectives}

After each observation, the teacher was asked to recount the lesson from his/her perspective, explicating thought processes and decisions that informed his/her teaching. A semi-structured interview was used. It is mentioned that 10 teachers were interviewed to obtain teachers' view regarding some issues related to SSC English teaching, testing, teaching materials and SSC English curriculum. All interviews were transcribed and read while listening to the audio recording. This exercise was particularly helpful in identifying elements of the recordings, such as a sarcastic tone, that were not apparent from the written transcript. The participants were given copies of the transcripts to check for accuracy, ensuring that the data collected was an appropriate representation of their attitudes, beliefs and perspectives. All the interview data were checked by participants with no amendments made. 
We asked teachers whether CLT approach is functional in SSC level.

Among the 10 participants 8 teachers provided similar responses with some minor variations. We considered one of the responses and cited it below as almost similar view was expressed by the participants.

T2 replied "I don't think that CLT based teaching exists in SSC level. We teachers do not clearly understand CLT principles. We think that our duty is to read the textbook/guide book or explain the grammar items in the class to prepare students for the test. If they score good grades everyone is happy. In real sense there are no communicative activities in the class. Though National curriculum directs us to teach to develop communication in an interactive classroom arrangement, teachers do not do that. Moreover, teachers do not need to teach all four major language skills because test includes only reading and writing skills. So, listening and speaking skills are hardly practised in the class".

From the above statement it is clear that the teaching, testing and learning activities at secondary level are not in line with CLT. Teachers identified that basic four language skills are not taught following the curriculum guidelines. Moreover, SSC English test also does not conform CLT principles because the test ignores listening and speaking skills.

However, two teachers: T4 and T9 believe that CLT is practised at SSC classrooms. T4 did not explain much. She stated that "I think CLT approach is followed at secondary level as per the direction of the Ministry". On the other hand T9 argued that "Our textbooks are following CLT. In textbooks there are so many communicative activities. The exam questions are written following CLT. Even the guidebooks that we use are written following CLT rules. Everything is now different from Grammar Translation method".

This is also interesting response. We understand there are teachers who even were not able to identify CLT features. They believed that as the curriculum states that CLT is functional, SSC level teaching is in line with CLT. However, these two teachers agreed that there are some hurdles in the implementation process of CLT. The following question revealed the hurdles those impede the implementation of CLT.

We also asked whether teachers used other additional materials besides textbooks.

All teachers acknowledged that besides textbooks they used guidebooks as they contain sufficient mock tests and answers to those. They opined that for the convenience of the students guidebooks are extremely helpful. When I observed their classes, I also observed that classes are exam directed and guidebooks are randomly consulted in the class.

Teachers were asked to ascertain the factors that impede the implementation of CLT at SSC level in Bangladesh. The following question was framed in this regard:

"What are the impediments to the implementation of CLT in Bangladesh?"

After analysing teachers' views, it was observed that 10 teacher participants expressed almost similar view where teachers opined that big class, untrained 
teachers, unequipped classroom, present testing system are hindering the implementation of CLT. A summary of the teachers' statements regarding the reasons that hindered the implementation of CLT found the following issues that impede the process of the implementation of CLT:

1) Lack of efficient teachers

2) Class size

3) Present (traditional) testing system and exclusion of listening and speaking skills test

4) Lack of acoustic facility in schools

However, four teachers (T3, T5, T7 \& T8) identified two additional factors that impede the implementation of CLT at SSC level in Bangladesh in response to the above-mentioned question. One of the responses cited here:

T 7 opined "the student population in a class, the lack of audio/video system, the poor quality of the students, exam pattern, and insufficient teachers with CLT training and English textbooks of NCTB are the main impediments to the implementation of CLT at SSC level in Bangladesh".

Here the rest of the three teachers' opinions are not cited as they expressed the same view. It was found that the above four teachers had added two more factors in addition to the above mentioned four other factors that hinder the implementation of CLT. Those factors are:

1) Present teaching and learning materials and

2) Students' uneven level of language proficiency.

In this stage, teacher participants' opinions regarding the impediments to the implementation of CLT in Bangladesh are accumulated and the following factors that impede the implementation of CLT are identified:

1) Lack of efficient and trained up teachers

2) Class size

3) Present (traditional) testing system

4) Lack of acoustic facility in schools

5) Present teaching and learning materials

6) Students' uneven level of language proficiency

\subsection{Discussion and Summary of the Findings}

From the data analysis, it is identified that SSC classroom teaching is largely test-centred and most classroom teaching is teacher-centric whereas CLT encourages learner autonomy in the classroom. As test items are predictable, teachers and learners have become test-wise and they massively practice those items which are regularly set in the test. In effect teacher dominated teaching-learning activities were noticed. Surely, these phenomena are contradictory with CLT approach.

The above analysis of the data showed that SSC EFL tests were not developed keeping harmony with CLT so far. Although it is officially claimed that the functional curriculum is CLT- based, data analysis showed that tests do not entirely follow the curriculum. There is no provision for testing Listening and Speaking 
skills and teachers also do not initiate any attempt to teach or practice these skills in the class. This is obviously against the practices of CLT (Eisenchlas, 2010: p. 15). The lack of acoustic facilities is also somehow responsible for teachers' reluctance of initiating listening and speaking sessions. All of these, in fact, largely hamper the implementation of CLT principles.

It should also be accepted that recent language teaching materials especially NCTB textbooks do not contain enough language activities that cover four skills. Materials on Speaking and Listening skills are required. The English syllabus that is followed now is also to some extent responsible behind the partial implementation of CLT. Lastly, students' uneven English language proficiency can be identified as another stumbling issue that impedes the implementation of CLT.

The official documents claim that the SSC English curriculum in Bangladesh is designed in line with the CLT approach. However, researchers have identified the gap between theory and practice. Numerous studies identified that CLT is not truly practised in the schools of Bangladesh (see Billah, 2015; Ali \& Walker, 2014; Hamid \& Baldauf, 2008; Haider \& Chowdhury, 2012).

It is generally accepted that CLT demands qualified and trained teachers because teachers without training will find it very difficult to implement. The TCG and NC acknowledge that English is a skill-based subject and no longer it should be considered as a content-based subject. It is a fact that most of the SSC level English teachers have not received adequate training or not at all received training (Hamid \& Baldauf, 2008). So, it is understood that teachers struggle to implement CLT principles in the classes where they teach. In addition to teachers' unpreparedness, the overpopulated classroom is also a big challenge for the teachers. The student population is around 80 to 90 in most of the classes. In such a crowded room it is really a tough task to implement CLT principles where learner-centred teaching is suggested by ensuring learner autonomy (see TCG).

By triangulating the findings of the data, it was evident that there were ten factors that impeded the implementation of CLT at SSC level in Bangladesh. A figure is produced below to demonstrate the factors that were considered as the impediments to the implementation of CLT at SSC level in Bangladesh from the data.

Figure 1 shows that there are as many as ten major factors that may be considered as the impediments to CLT in Bangladesh at SSC level. The identified factors are lack of efficient teachers, class size, exam-oriented teaching culture, teacher dominated teaching-learning culture, present (traditional) testing system, lack of acoustic facility in schools, present teaching and learning materials, students' uneven level of language proficiency, present SSC English syllabus and Classroom communication/Language used.

From the above data analysis it is revealed that the CLT-based curriculum is not functional at SSC level in true sense. There remains strong presence of GTM at the secondary level. Neither the teaching activities nor the used test were found to align with the CLT principles (Wei, Lin, \& Litton, 2018). The data explored 


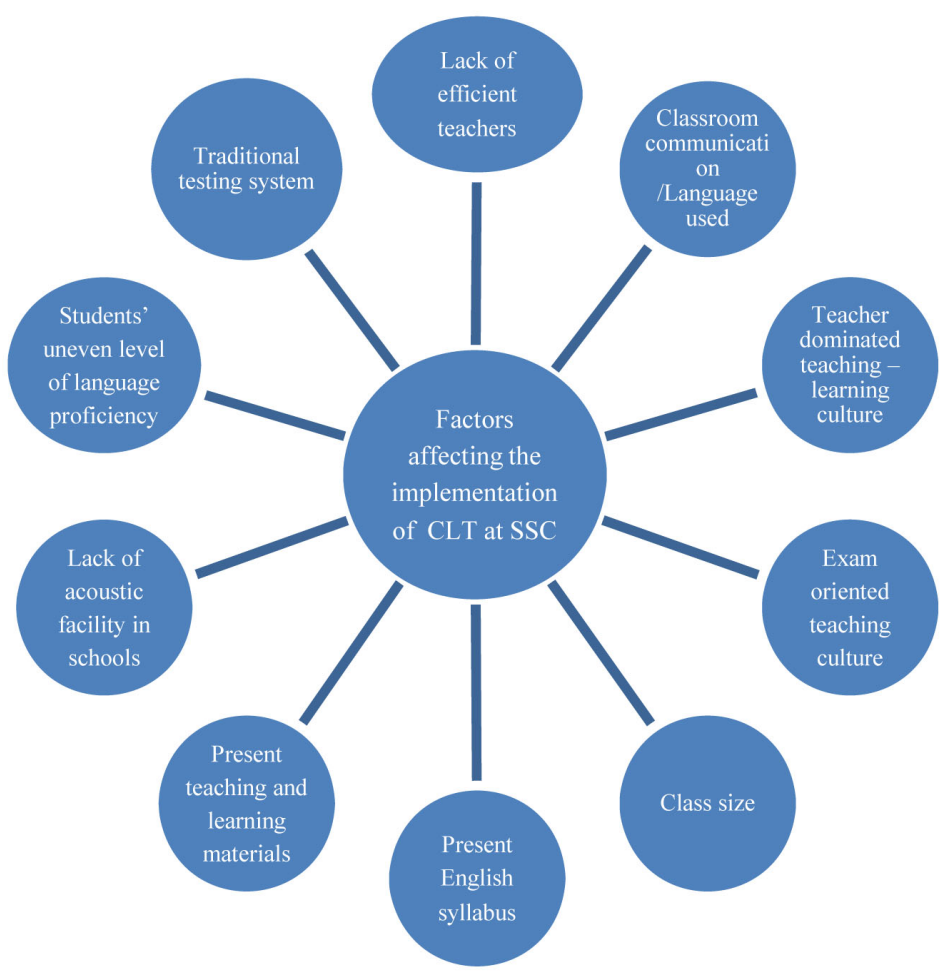

Figure 1. Impediments to CLT.

the above mentioned ten mentionable impediments that hindered the implementation of CLT. The authority concerned could have considered the issue of teacher's training, testing, classroom environment, teaching materials and contextual limitations more seriously prior to introducing CLT. Understandably, it is a fact that ground realities were ignored when CLT was introduced at the secondary level in Bangladesh. Arguably, policymakers were largely responsible for this state of mismatch.

\section{Conclusion}

Despite the fact that CLT curriculum is officially functional at secondary level in Bangladesh, so far CLT is not completely implemented. Our study identified that CLT has not been implemented yet in true sense in the schools. As per the curriculum, not only teaching but also testing of English should be aligned with CLT. The curricular guidelines are clearly violated so far. This study identified some specific factors which are hindering the implementation process of the CLT curriculum. Enough time is spent since the inception of CLT. The authority concerned should adopt pragmatic steps to address problems identified. Otherwise, the purpose of introducing a communicative curriculum shall never be achieved.

\section{Conflicts of Interest}

The authors declare no conflicts of interest regarding the publication of this paper. 


\section{References}

Ali, M. M., Hamid, M. O., \& Hardy, I. (2018). Ritualisation of Testing: Problematising High-Stakes English-Language Testing in Bangladesh. Compare: A Journal of Comparative and International Education, 1-21. https://doi.org/10.1080/03057925.2018.1535890

Ali, M., \& Walker, A. L. (2014). “Bogged Down” ELT in Bangladesh: Problems and Policy: Investigating Some Problems That Encumber ELT in an EFL Context. English Today, 30, 33-38. https://doi.org/10.1017/S0266078414000108

Anam, M. (2019). Rise in SSC Pass Rates Commendable Stress Should Be on Quality of Education. The Daily Star, 6.

Begum, M., \& Farooqui, S. (2008). School Based Assessment: Will It Really Change the Education Scenario in Bangladesh? International Education Studies, 1, 45-53. https://doi.org/10.5539/ies.v1n2p45

Billah, M. (2015). Language and Education Inside and Beyond the Classroom, Murdhonno, Dhaka, Bangladesh.

Bloomberg, L. D., \& Volpe, M. (2018). Completing Your Qualitative Dissertation: A Road Map from Beginning to End. Thousand Oaks, CA: Sage Publications.

Bogdan, R. C., \& Biklen, S. K. (2007). Qualitative Research for Education: An Introduction to Theory and Methods (5th ed.). Boston, MA: Pearson.

Creswell, J. W. (2013). Qualitative Inquiry and Research Design: Choosing among Five Approaches (3rd ed.). Thousand Oaks, CA: Sage.

Dolores, M., \& Tongco, C. (2007). Purposive Sampling as a Tool for Informant Selection. Ethnobotany Research \& Applications, 5, 147-158. https://doi.org/10.17348/era.5.0.147-158

Eisenchlas, S. (2010). Conceptualising "Communication" in Foreign Language Instruction. Babel, 44, 12.

Haider, M. Z., \& Chowdhury, T. A. (2012). Repositioning of CLT from Curriculum to Classroom: A Review of the English Language Instructions at Bangladeshi Secondary Schools. International Journal of English Linguistics, 2, 12-22. https://doi.org/10.5539/ijel.v2n4p12

Hamid, M. O. C., \& Baldauf, R. B. (2008). Will CLT Bail out the Bogged down ELT in Bangladesh? English Today, 24, 16-24. https://doi.org/10.1017/S0266078408000254

Hymes, D. H. (1979). On Communicative Competence. In C. J. Brumfit, \& K. Johnson (Eds.), The Communicative Approach to Language Teaching (pp. 5-26). Malta: Oxford University Press.

Islam, A. S. M. (2015). Language Policy and Practice in Secondary School Contexts in Bangladesh: Challenges to the Implementation of Language-in-Education Policy. Unpublished Doctoral Dissertation, Denmark: Aalborg University.

Jamila, F., \& Kabir, M. H. (2020). Examining the Existence of "Teaching to the Test" at SSC Level in Bangladesh. Creative Education, 11, 558-572. https://doi.org/10.4236/ce.2020.114041

Kabir, M. H. (2008). How Validity Is Ensured in Our Language Test: A Case Study. IIUC Studies, 5, 37-52.

Kabir, M. H. (2009). How Much Reliable Are Our Language Tests? A Case Study. Crossings, ULAB Journal of English Studies, 2, No. 1.

Kabir, M. H. (2015a). Managing Curricular Innovation and Teacher Training: Bangladesh Perspective. IIUC Studies, 12, 9-26. https://doi.org/10.3329/iiucs.v12i0.30578

Kabir, M. H. (2015b). Effect of Bangladeshi English Language Testing on Teaching and Learning: A Case Study. The International Institute for Science, Technology and Education (IISTE). 
Kabir, M. H., \& Saad, N. S. B. (2020). Assessing the Interdependence of SSC EFL Testing, Teaching and Materials; an Evaluation of SSC Curriculum. Creative Education, 11, 16-37. https://doi.org/10.4236/ce.2020.111002

Mariyam, T., Kabir, M. H., \& Ullah, M. M. (2015). Casting the Authority or Holding It Still: An Investigation of Teachers' Role in CLT Classrooms in Bangladesh. The International Journal of social Science, 37, 133-146. http://www.Tijoss.com

Marshall, C., \& Rossman, G. B. (1989). Designing Qualitative Research. Newbury Park, CA: Sage.

Merriam, S. B. (2009). Qualitative Research: A Guide to Design and Implementation. San Francisco, CA: Jossey-Bass.

Miles, M. B., \& Huberman, A. M. (1994). Qualitative Data Analysis: An Expanded Source Book (2nd ed.). Thousand Oaks, CA: Sage Publication.

National Curriculum (NCTB) (2012). English Classes VI-X. Dhaka: National Curriculum \& Textbook Board.

Pan, Y. C. (2013). A Closer Examination of Communicative Language Teaching. Studies in Literature and Language, 6, 40.

Pervez, R. (2016). Guidebook Dependent Creative Method, (in Search for Advancement of Complete Education (RACE). The Daily Azadi, 1.

Punch, K. F. (2005). Introduction to Social Research-Quantitative and Qualitative Approaches $(320$ p.). London: Sage.

Rahman, M. M., \& Pandian, A. (2018). A Critical Investigation of English Language Teaching in Bangladesh: Unfulfilled Expectations after Two Decades of Communicative Language Teaching. English Today, 34, 43-49. https://doi.org/10.1017/S026607841700061X

Rahman, M. M., Singh, M. K. M., \& Pandian, A. (2018). Exploring ESL Teacher Beliefs and Classroom Practices of CLT: A Case Study. International Journal of Instruction, 11, 295-310. https://doi.org/10.12973/iji.2018.11121a

Rahman, S. (2015). English Language Policy Initiatives and Implementation in Bangladesh: Micro political Issues. Asian EFL Journal, 88, 59-96.

Saad, N. S. B. M. (2014). The English Language Learning Experiences of International Students. PhD Thesis (Unpublished), Bangi: Universiti Kebangsaan Malaysia.

Silverman (2000). Doing Qualitative Research: A Practical Handbook. Thousand Oaks, CA: Sage Publications Ltd.

Sultana, N. (2018). Test Review of the English Public Examination at the Secondary Level in Bangladesh. Language Testing in Asia, 8, Article No. 16. https://doi.org/10.1186/s40468-018-0068-1

Sultana, N. (2019). Language Assessment Literacy: An Uncharted Area for the English Language Teachers in Bangladesh. Language Testing in Asia, 9, Article No. 1. https://doi.org/10.1186/s40468-019-0077-8

Taqizadeh, M., \& Birjandi, P. (2015). What Drives High School English Teachers to Teach the Way They Do? An Investigation of the Washback Effect of the University Entrance Examination in Iran. Journal of Applied Linguistics and Language Research, 2, 8-20.

Teacher's Curriculum Guide (2013). National Curriculum Textbook Board. Dhaka, Bangladesh.

Wei, L., Lin, H. H., \& Litton, F. (2018). Communicative Language Teaching (CLT) in EFL Context in Asia. Asian Culture and History, 10, 1-9.

https://doi.org/10.5539/ach.v10n2p1 